Article

\title{
Preventive Activity against Influenza (H1N1) Virus by Intranasally Delivered RNA-Hydrolyzing Antibody in Respiratory Epithelial Cells of Mice
}

\author{
Seungchan Cho ${ }^{1, \dagger}$, Ha-Na Youn ${ }^{2, \dagger}$, Phuong Mai Hoang ${ }^{1, \dagger}$, Sungrae Cho ${ }^{1}$, Kee-Eun Kim ${ }^{1}$, \\ Eui-Joon Kil ${ }^{1}$, Gunsup Lee ${ }^{1}$, Mun-Ju Cho ${ }^{1}$, Juhyun Hong ${ }^{1}$, Sung-June Byun ${ }^{3}$, \\ Chang-Seon Song ${ }^{2, *}$ and Sukchan Lee ${ }^{1, *}$ \\ Received: 7 July 2015 ; Accepted: 14 September 2015 ; Published: 21 September 2015 \\ Academic Editor: Curt Hagedorn \\ 1 Department of Genetic Engineering, Sungkyunkwan University, 2066, Seobu-ro, Jangan-gu, Suwon 16419, \\ Korea; seungchan1007@gmail.com (S.C.); hmphuong2802@gmail.com (P.M.H.); \\ sungle89@gmail.com (S.C.); happykke6@naver.com (K.-E.K.); meitantei007@naver.com (E.-J.K.); \\ asteroid1975@gmail.com (G.L.); munju2004@naver.com (M.-J.C.); rsef741@gmail.com (J.H.) \\ 2 Avian Disease Laboratory, College of Veterinary Medicine, Konkuk University, 120, Neungdong-ro, \\ Gwangjin-gu, Seoul 05029, Korea; yellow0891@daum.net \\ 3 Animal Biotechnology Division, National Institute of Animal Science (NIAS), Rural Development \\ Administration (RDA), 1500, Kongjwipatjwi-ro, Iseomyeon, Wanju 55365, Korea; pcs1778@korea.kr \\ * Correspondence: songcs@konkuk.ac.kr (C.-S.S.); cell4u@skku.edu (S.L.); Tel.: +82-2-710-9396 (C.-S.S.); \\ +82-31-290-7866 (S.L.); Fax: +82-2-2077-7322 (C.-S.S.); +82-31-290-7870 (S.L.) \\ $\dagger$ These authors contributed equally to this work.
}

\begin{abstract}
The antiviral effect of a catalytic RNA-hydrolyzing antibody, 3D8 scFv, for intranasal administration against avian influenza virus (H1N1) was described. The recombinant 3D8 scFv protein prevented BALB/c mice against H1N1 influenza virus infection by degradation of the viral RNA genome through its intrinsic RNA-hydrolyzing activity. Intranasal administration of 3D8 scFv ( $50 \mu \mathrm{g} /$ day) for five days prior to infection demonstrated an antiviral activity ( $70 \%$ survival) against H1N1 infection. The antiviral ability of 3D8 scFv to penetrate into epithelial cells from bronchial cavity via the respiratory mucosal layer was confirmed by immunohistochemistry, qRT-PCR, and histopathological examination. The antiviral activity of 3D8 scFv against H1N1 virus infection was not due to host immune cytokines or chemokines, but rather to direct antiviral RNA-hydrolyzing activity of 3D8 scFv against the viral RNA genome. Taken together, our results suggest that the RNase activity of 3D8 scFv, coupled with its ability to penetrate epithelial cells through the respiratory mucosal layer, directly prevents H1N1 virus infection in a mouse model system.
\end{abstract}

Keywords: 3D8 scFv; antiviral effect; influenza virus; intranasal administration; nuclease activity; respiratory mucosal layer

\section{Introduction}

Influenza virus, a RNA virus in the family Orthomyxoviridae is an acute respiratory infectious agent that causes significant morbidity and mortality in annual epidemics and global pandemic outbreaks [1]. In 2009, the pandemic H1N1 influenza A emerged from Mexico and the United States [2,3]. During the initial phases of the $2009 \mathrm{H} 1 \mathrm{~N} 1$ pandemic, the use of neuraminidase inhibitors for the prevention of influenza virus infection was effective when vaccines were not available [4]. However, seasonal and 2009 pandemic H1N1 influenza viruses that are resistant to these drugs have emerged and subsequently spread worldwide [5,6]. In addition, increased influenza activity was reported in North America and Europe and in several countries in 
Asia in 2014. Over the years, many mutant influenza viruses such as $\mathrm{A}(\mathrm{H} 1 \mathrm{~N} 1) \mathrm{pdm} 09$ and $\mathrm{A}(\mathrm{H} 3 \mathrm{~N} 2)$ have been identified, posing a great threat to worldwide public health $[7,8]$. Therefore, there is an urgent need for the development of novel antiviral therapeutics against new influenza viruses or their mutants.

3D8 $\mathrm{scFv}$ is an anti-DNA/RNA antibody that binds and hydrolyzes nucleic acids without significant sequence specificity [9]. This antibody was originated from an autoimmune-prone MRL-lpr/lpr mouse [10]. The 3D8 scFv protein was initially purified from E. coli and was subsequently shown to penetrate into the cytosol of HeLa cells via caveolae-mediated endocytosis [11]. Importantly, 3D8 scFv exhibits antiviral effects against herpes simplex virus (HSV), pseudorabies virus (PRV) and classical swine fever virus (CSFV) for prevention in transgenic HeLa and PK15 cells respectively $[12,13]$. In addition, 3D8 scFv also therapeutically protected RAW264.7 cells, macrophages of mouse, against murine norovirus (MNV) infection [14]. Based on these findings, it is clear that 3D8 scFv has antiviral effects against various DNA and RNA viruses in both in vivo and in vitro systems by penetrating into cells and directly catalyzing the hydrolysis of the viral genome.

Many infectious agents must enter the body at mucosal surfaces, and thus the mucosal layer functions as a first line of defense against infection [15]. Recently, the use of the nasal and pulmonary routes for the delivery of drugs and vaccines, especially against respiratory infections such as influenza, has attracted interest from pharmaceutical companies [16-18]. Numerous studies have investigated nasal delivery systems as a way to boost the host immune response as well as to deliver protein drugs $[16,17]$. Intranasal administration of a peptide of apoB-100 that was fused to the B subunit of cholera toxin (CTB) caused a 35\% reduction in atherosclerosis in $\mathrm{Apoe}^{-/-}$mice by the induction of regulatory $\mathrm{T}$ cells [19]. In another study, a nasal anthrax vaccine composed of nasal protective antigen (PA) fused with liposome-protamine-DNA (LPD) particles was developed for better protection against inhalational anthrax infection [20]. However, it is currently unknown whether protein drugs can efficiently pass through the respiratory mucosal layer to enter epithelial cells. Thus, verification of the ability of protein drugs to pass through the respiratory mucosal layer is important for the continued development of such approaches.

In this study, we tested the ability of intranasally administered 3D8 scFv protein to directly protect BALB/c mice against H1N1 influenza virus infection in the lung. Our results showed that administration of 3D8 scFv for 5 days prior to infection had strong antiviral effects against A/NWS/33 H1N1 influenza virus. To our knowledge, this is the first report showing that 3D8 scFv has antiviral effects against an RNA virus in an in vivo mouse model system through its intrinsic RNA-hydrolyzing activity coupled with its ability to penetrate into epithelial cells via the respiratory mucosal layer.

\section{Materials and Methods}

\subsection{Animals}

Six-week-old female specific pathogen-free (SPF) BALB/c mice (Orient Bio Laboratories, Seongnam, Korea) weighing 18-20 g were housed under standard laboratory conditions. All animal procedures performed in this study (permit number: KU15006) were reviewed, approved, and supervised by the Institutional Animal Care and Use Committee (IACUC) of Konkuk university.

\subsection{Virus and Cell Culture}

Madin-Darby Canine Kidney epithelical cells (MDCK cells) were provided by the Korean Cell Line Bank and were maintained in Eagle's minimal essential medium (MEM) containing 5\% fetal bovine serum (Hyclone, Logan, UT, USA), $100 \mathrm{U} / \mathrm{mL}$ penicillin- streptomycin (Hyclone) at $37{ }^{\circ} \mathrm{C}$ in a $5 \% \mathrm{CO}_{2}$ atmosphere. Influenza A/NWS/33 (H1N1) virus (ATCC ${ }^{\circledR}$ VR-219 ${ }^{\mathrm{TM}}$ ) was purchased from the American Type Culture Collection (ATCC) and was grown in the allantoic sacs of 11-day-old chicken embryos at $37^{\circ} \mathrm{C}$ for 2 days. The allantoic fluid was prepared as described 
previously [21]. For challenge studies, mice were anesthetized with an intraperitoneal injection of Avertin $(375 \mathrm{mg} / \mathrm{kg})$, followed by intranasal administration of $100 \mu \mathrm{L}$ of $10^{4} \mathrm{EID}_{50}$ influenza virus.

\subsection{Virus Infection to MDCK Cells}

MDCK cells were infected with $200 \mu \mathrm{L}$ of $10^{3} \mathrm{EID}_{50}$ influenza virus in serum-free DMEM for $40 \mathrm{~min}$, washed, and incubated for $24 \mathrm{~h}$ in serum-free DMEM with trypsin $(1 \mu \mathrm{g} / \mathrm{mL})$. Cytopathic effects were observed by microscopy. Cells were lysed in TRIzol reagent (Molecular Research Center, Inc., Cincinnati, OH, USA) for RNA extraction. After generating complementary DNA, viral RNA expression in MDCK cells was determined using quantitative real-time PCR. All values were normalized against GAPDH cDNA using the $2^{-\Delta \Delta C t}$ method.

\subsection{HA RNA Transcript Preparation and RNA Hydrolyzing Activity Test}

Hemagglutinin (HA) cDNA was synthesized from total RNA isolated from H1N1-infected MDCK cells and cloned into pGEM ${ }^{\circledR}-\mathrm{T}$ Easy, a vector that harbors the T7 promoter (Promega, Madison, WI, USA). The specific primers for HA were as follows: HA forward primer, $5^{\prime}$-ATG AAG GCA AAA CTA CTG GTC C-3'; HA reverse primer, 5'-AGT AGA AAC AAG GGT GTT TTT TCT-3'. HA RNA was synthesized from the cloned cDNA using an in vitro transcription kit (HiScribe T7 In Vitro Transcription; New England BioLabs, Ipswich, MA, USA) and incubated with 3D8 scFv purified protein $(0.5 \mu \mathrm{g})$ for $1 \mathrm{~h}$ in TBS containing $2 \mathrm{mM} \mathrm{MgCl}_{2}$ at $37^{\circ} \mathrm{C}$. Reactions were terminated by addition of $10 \times$ loading buffer and analyzed by electrophoresis on $1 \%$ agarose gels and staining with ethidium bromide.

\subsection{Purification of $3 D 8 s c F v$ Protein}

3D8 $\mathrm{scFv}$ protein was expressed in bacteria and purified by IgG-Sepharose affinity chromatography as described previously [9]. Protein concentrations were determined using an extinction coefficient for $\mathrm{scFv}$ of 1.995 , in units of $\mathrm{mg} \cdot \mathrm{mL}^{-1} \cdot \mathrm{cm}^{-1}$ at $280 \mathrm{~nm}$, which was calculated from the amino acid sequence. Endotoxin content was determined using the Limulus Amebocyte Lysate (LAL) assay (PYROGENT ${ }^{\mathrm{TM}} 25$ single tests $0.125 \mathrm{EU} / \mathrm{mL}$ sensitivity, Lonza, Basel, Switzerland). The LAL assay was performed in pyrogen-free tubes to which $0.1 \mathrm{~mL}$ of 3D8 scFv protein $(20 \mu \mathrm{g}$ and $50 \mu \mathrm{g})$ and LAL reagent were added. After $1 \mathrm{~h}$ incubation at $37^{\circ} \mathrm{C}$, the tubes were observed by vertical inversion to see whether a stable solid clot was present or not. A visible solid clot was not observed in test tubes containing $3 \mathrm{D} 8 \mathrm{scFv}$ protein. The values of $3 \mathrm{D} 8 \mathrm{scFv}$ endotoxicity was $<0.125 \mathrm{EU} \cdot \mathrm{mL}^{-1}$.

\subsection{Intranasal Administration of $3 D 8 s c F v$ Protein}

Mice were treated with $20 \mu \mathrm{g}$ or $50 \mu \mathrm{g}$ of 3D8 scFv protein for 3 or 5 days (Figure 2). PBS was given to the control groups for 5 days before challenge. After challenge with H1N1 influenza virus, clinical signs were observed daily for 14 days post-infection (p.i.). As a control, four mice from the group treated with $50 \mu \mathrm{g}$ 3D8 scFv for 5-day were sacrificed on day 0 p.i., and lung samples were collected for histopathological examination.

\subsection{Immunohistochemistry and Histopathological Examination}

Lungs were collected from each group and fixed in 10\% PFA. All samples were dipped in $4 \%$ sucrose in PBS, embedded, frozen, and sectioned using a cryomicrotome (Leica CM3050S, Wetzlar, Germany). The 10- $\mu \mathrm{m}$-thick lung tissue sections for immunohistochemistry were mounted on silane-coated slides as described previously [22]. Tissue sections were incubated with rabbit anti-3D8 scFv and rabbit anti-HA primary antibodies (1:100 dilutions) for $1 \mathrm{~h}$ at room temperature. The tissue sections were incubated respectively with a TRITC-conjugated anti-rabbit secondary $\mathrm{Ab}$ (1:500 dilutions) to both anti-3D8 and anti-HA antibodies-incubated tissue section and visualized 
using a fluorescence microscope (Nikon Eclipse 80, Tokyo, Japan). For histopathological examination, samples were stained with hematoxylin and eosin (H\&E) for microscopic examination and viewed under microscope (Nikon Eclipse E400).

\subsection{Determination of Virus Titer}

A lung from each mouse was homogenized in liquid nitrogen and resuspended in PBS. Measurement of the virus titer was performed as described previously [21].

\subsection{Measurement of Cytokine and Chemokine Levels}

Total RNA was extracted from lysed lung tissue using an Easy-spin Total RNA prep kit (Intron, Seongnam, Korea). cDNA was synthesized from $5 \mu \mathrm{g}$ of total RNA using oligo-dT and Moloney murine leukemia virus (MMLV) reverse transcriptase (LexgeneBio, Cheongju, Korea). All primers were designed using the Primer 3 program [23] and are listed in Table 1. Levels of interferon-gamma (IFN- $\gamma$ ), tumor necrosis factor alpha (TNF- $\alpha$ ), and interleukin- 6 expression were determined by qRT-PCR as described previously.

Table 1. Specific primers for qRT-PCR.

\begin{tabular}{cccc}
\hline & Forward & Reverse & Accession No \\
\hline GAPDH & TGG CAA AGT GGA GAT TGT TGC C & AAG ATG GTG ATG GGC TTC CCG & NM_002046 \\
3D8 scFv & TAT GCA CTG GGT GAA GCA GA & TGA GCT CCA TGT AGG CTG TG & AF232220 \& AF232221 \\
Hemagglutinin & CAC CCG TCT AGC AGT GAT GA & CTC AGT GCG AAA GCA TAC CA & U08903.1 \\
Neuraminidase & CAC TTG GAA TGC AGG ACC TT & ACC AAG CAA CCG ATT CAA AC & HQ008256.1 \\
TNF-alpha & CGT CAG CCG ATT TGC TAT CT & CGG ACT CCG CAA AGT CTA AG & NM_013693.2 \\
IL-6 & AGT TGC CTT CTT GGG ACT GA & TCC ACG ATT TCC CAG AGA AC & NM_031168.1 \\
IFN-gamma & ACT GGC AAA AGG ATG GTG AC & GAC CTG TGG GTT GTT GAC CT & NM_008337.3 \\
\hline
\end{tabular}

\subsection{Statistical Analysis}

All statistical analyses were performed using the GraphPad Prism software (GraphPAD Software). Kaplan-Meier survival curves were generated and compared using the Mantel-Cox log-rank test to determine statistical significance [24]. One-way ANOVA and Tukey's post hoc $t$-tests were used for statistical analyses. Data are presented as means \pm SEMs.

\section{Results}

\subsection{Direct RNA Hydrolyzing Activity of 3D8 scFv against H1N1 Influenza Virus in MDCK Cells}

Based on research showing that 3D8 scFv could catalyze the viral genome and its transcripts [12], we tested the antiviral activity of endotoxin-free 3D8 scFv by treatment of purified 3D8 scFv proteins to MDCK cells. The cells were subsequently infected with $200 \mu \mathrm{L}$ of $10^{3} \mathrm{EID}_{50} \mathrm{H} 1 \mathrm{~N} 1$ influenza virus in serum-free DMEM for $40 \mathrm{~min}$, washed with PBS, and incubated for $24 \mathrm{~h}$ in serum-free DMEM with trypsin $(1 \mu \mathrm{g} / \mathrm{mL})$ in a $37^{\circ} \mathrm{C} \mathrm{CO}_{2}$ incubator. At $24 \mathrm{~h}$ post-infection, a less cytopathic effect (CPE) was observed under the microscope in the cells treated with 3D8 scFv compared with those treated with PBS (Figure 1A). The expression levels of hemagglutinin (HA) and neuraminidase (NA) were decreased approximately 10 -folds in the 3D8 scFv-treated group compared with the PBS-treated group (Figure 1B,C). To determine the direct catalytic activity of 3D8 scFv against influenza virus, we tested the RNA hydrolyzing assay against the HA transcript of H1N1 influenza virus. Treatment with PBS for a prolonged incubation period did not result in degradation of mRNA, whereas purified $3 \mathrm{D} 8 \mathrm{scFv}$ protein resulted in an obvious time-dependent hydrolysis, as shown by a smeared mRNA pattern on a $1 \%$ agarose gel (Figure 1D). 
A
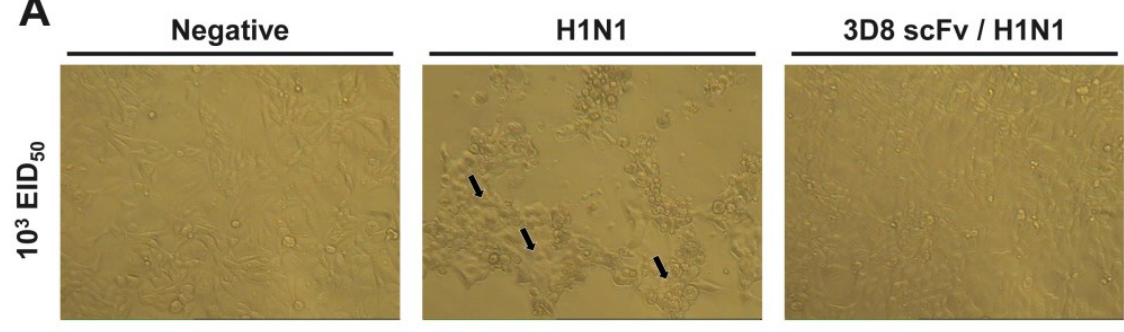

B

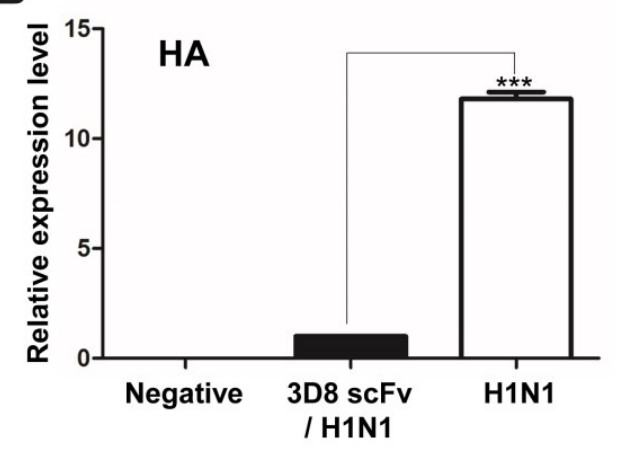

C

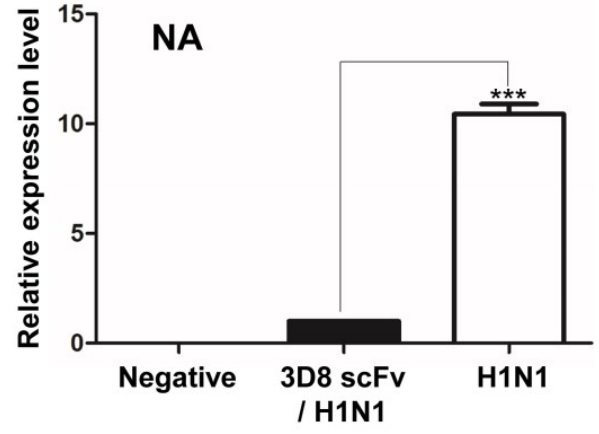

D

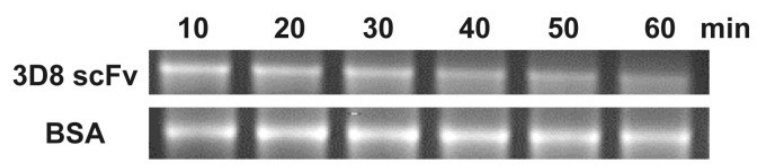

Figure 1. Direct catalytic activity of 3D8 scFv against H1N1 influenza virus. Madin-Darby Canine Kidney epithelical cells (MDCK cells) were infected with $200 \mu \mathrm{L}$ of $10^{3}$ EID $_{50}$ influenza virus for $4 \mathrm{~h}$ and then incubated for $24 \mathrm{~h}$ in serum-free medium with trypsin $(1 \mu \mathrm{g} / \mathrm{mL})$. (A) The cytopathic effects were examined by microscopy. Magnification $100 \times$. The arrows indicated the cytopathic effects on host cells caused by H1N1 infection; (B) Transcripts of hemagglutinin and neuraminidase were measured by qRT-PCR and normalized by against GAPDH cDNA using the $2^{-\Delta \Delta C t}$ method. Data are shown as mean \pm S.E.M of triplicate samples from three independent experiments. Data are mean \pm standard error. ${ }^{* *}$ Significantly different from 3D8 scFv/H1N1 group at $p<0.001$ (one-way analysis of variance and Tukey's post hoc t-test); (C) The RNA transcript of hemagglutinin was incubated with 3D8 scFv purified protein for $1 \mathrm{~h}$; (D) Reactions were terminated at 10, 20, 30, 40, 50 and $60 \mathrm{~min}$ and analyzed by electrophoresis.

\subsection{Recovery from H1N1 Infection in Mice Treated with $3 D 8 s c F v$}

To determine the protective effect of 3D8 scFv according to dose and number of injections, we pre-administered 3D8 scFv intranasally at two different doses (20 or $50 \mu \mathrm{g} /$ day) for 3 or 5 days, and then challenged the mice with H1N1 influenza virus (Figure 2A). All of the mice in the control group were dead by day 13 . In contrast, after 15 days we observed the survival rates of $50 \%$ and $70 \%$ in the groups treated with $50 \mu \mathrm{g} /$ day $3 \mathrm{D} 8 \mathrm{scFv}$ for 3 or 5 days respectively. Likewise, mice that were pretreated with $20 \mu \mathrm{g}$ /day 3D8 scFv for 3 or 5 days showed survival rates of $20 \%$ and $40 \%$, respectively (Figure 2B). Weight loss in the control group progressed continuously after H1N1 influenza virus infection, whereas the weights of mice that were pretreated with 3D8 scFv decreased slightly after H1N1 influenza virus infection to normal by 8-10 days p.i. (Figure 2C). Overall, the group that was pretreated with $50 \mu \mathrm{g} /$ day 3D8 scFv for 5 days exhibited the highest antiviral clinical efficacy among the groups analyzed. Therefore, we selected this group for further evaluation. Virus titers in lung tissues measured on 3 and 6 days p.i. are shown in Figure 3A. Virus titers in the lung decreased as a function of time in the 3D8 scFv-treated group but showed at high levels in the control group, compared with the $3 \mathrm{D} 8 \mathrm{scFv}$ pretreated group at 3 and 6 days p.i. (Figure 3A). 


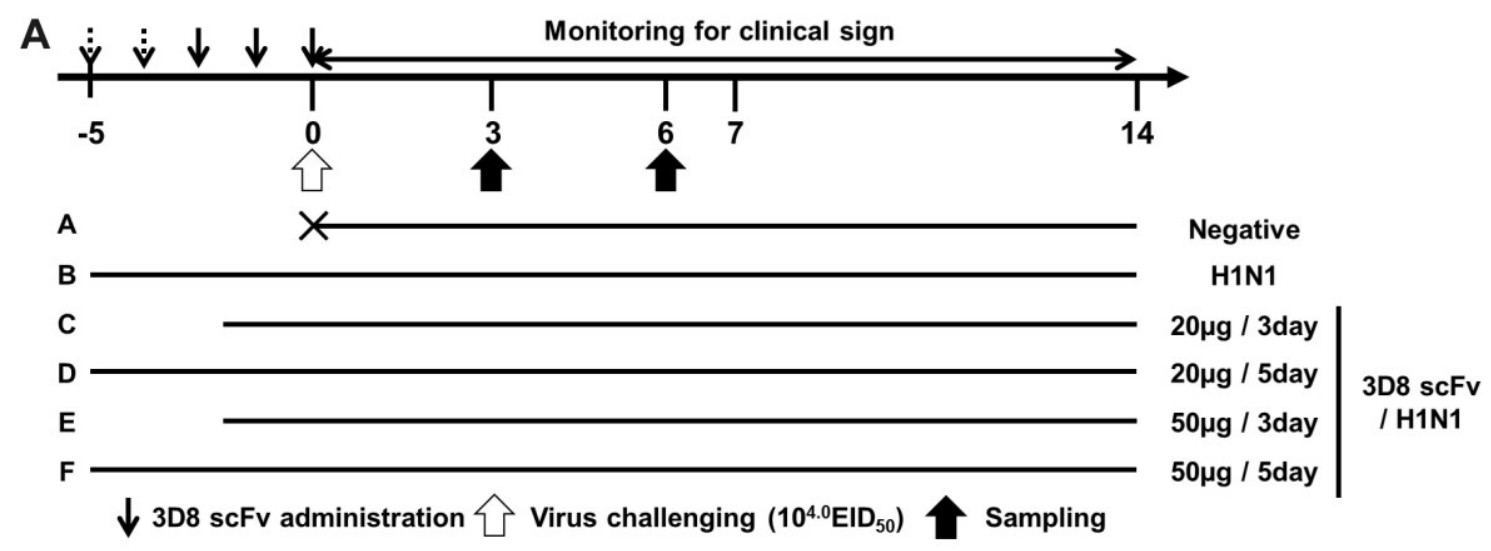

B

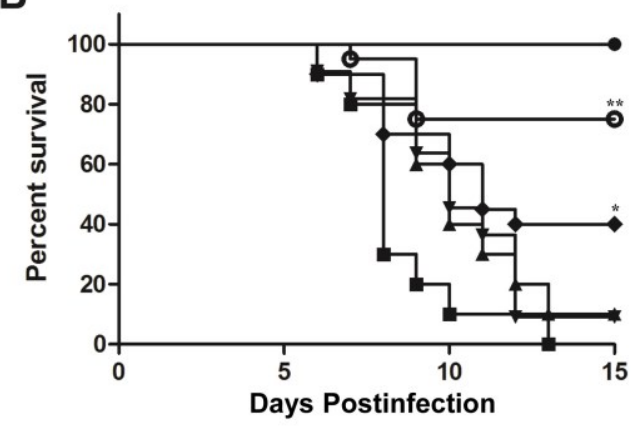

C

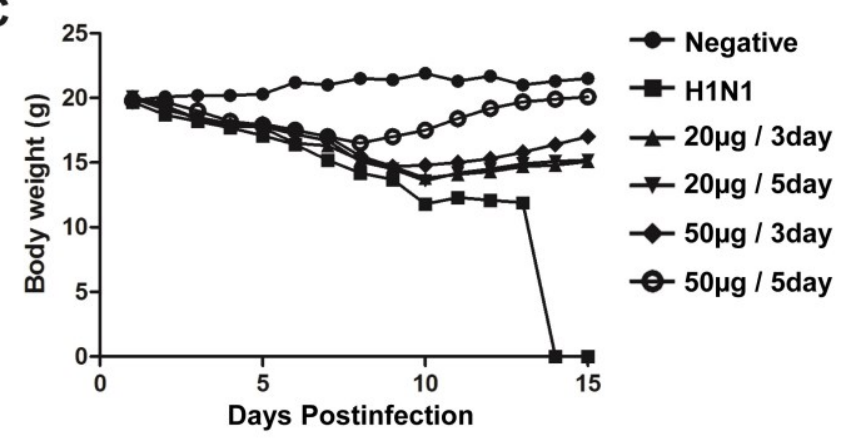

Figure 2. Antiviral effects of intranasally administrated $3 \mathrm{D} 8 \mathrm{scFv}$ on survival and body weight. (A) BALB/c mice were treated intranasally with 3D8 scFv protein (50 $\mu \mathrm{g} / \mathrm{mouse})$ for 3 or 5 days before infection with A/NWS/33; $(B, C)$ Mice were monitored daily for 14 days to determine the rate of survival (B) and changes in body weight (C). Control group, $n=10$; positive control group, $n=10$; treatment groups, $n=10$. Asterisks indicate significant differences $\left(* p<0.05,{ }^{* *} p<0.01\right)$ compared with the positive (H1N1) control group (Fisher's exact test).

\subsection{Reduced Influenza Virus Pathogenicity Due to the Preventive Effect of 3D8 scFv in the Lung}

To confirm that the differences in clinical signs between the control and 3D8 scFv pretreated groups were due to a reduction in influenza virus pathogenicity, the expression levels of genes related to viral replication were evaluated by qRT-PCR using lung RNA samples obtained from the experiments described above. As shown in Figure 3B, expression of HA and NA mRNA was elevated in the control group, but significantly reduced in the $3 \mathrm{D} 8 \mathrm{scFv}$ pretreated group (Figure 3B). Consistent with the qRT-PCR results, immunohistochemistry showed that production of HA protein was inhibited in the 3D8 scFv pretreated group versus the control group (Figure 3C).

\subsection{D8 scFv Reduced Histopathological Symptoms in Mouse Lung Tissue}

We performed a histopathological examination by H\&E staining to investigate the changes in cell shapes after virus infection. After H1N1 infection, the degree of infiltration of dense granulocytic and lymphocytic cells in the interstitium and around vessels and airways was less in the 3D8 scFv pretreated group than in the control group (Figure 3Df,1). Additionally, focally denuded lamina propria, attributed to epithelial necrosis and desquamation, was observed to a greater extent in the control group (Figure 3De,k). 
A

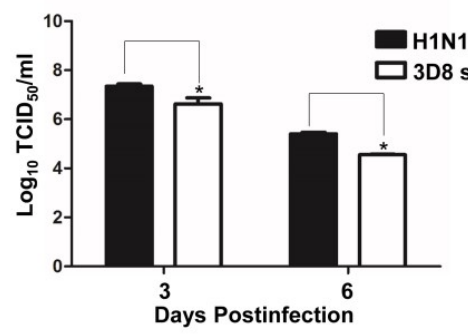

B
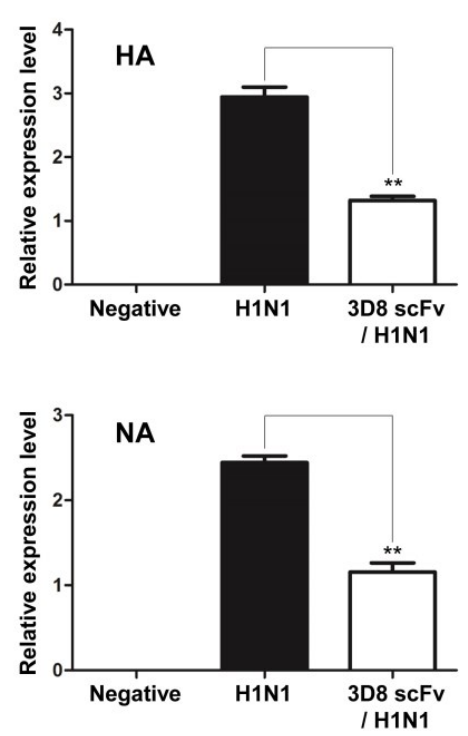

C

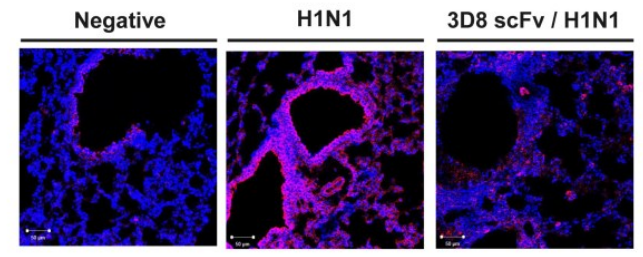

D

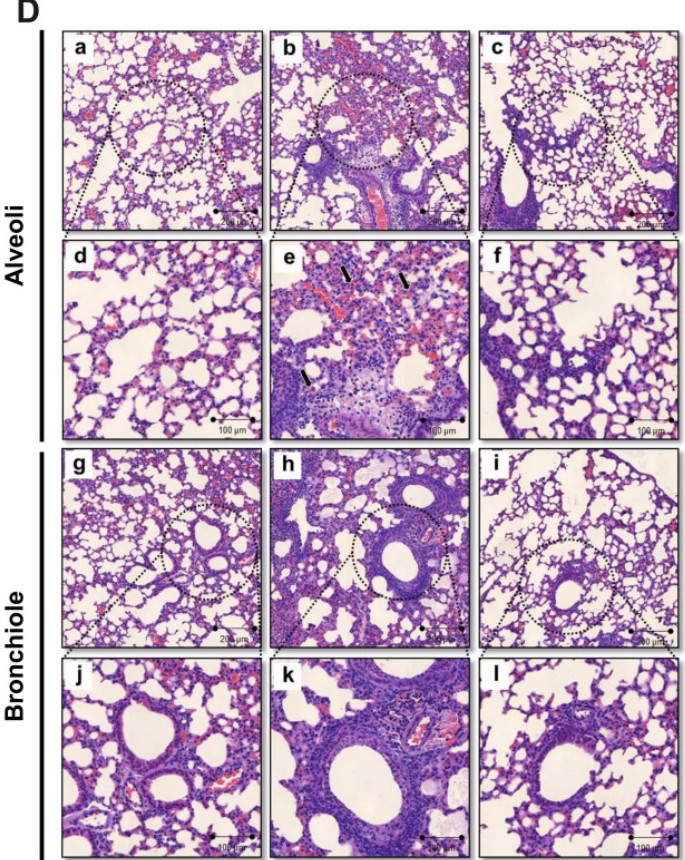

Figure 3. Preventative antiviral effects of $3 \mathrm{D} 8 \mathrm{scFv}$ protein in the lung. Emulsion samples were extracted from lung tissue after virus infection. (A) The viral titer was measured by $\mathrm{TCID}_{50}$ assay; (B) Viral replication was analyzed by qRT-PCR; (C) To confirm viral protein expression, H1N1 HA protein was detected by confocal microscopy using antibodies specific for HA and GAPDH. Asterisks indicate significant differences $(* p<0.05, * *<0.01$ ) versus the positive (H1N1) control group (one-way analysis of variance and Tukey's post hoc t-test); (D) Photomicrographs of lung sections in H1N1-infected mice treated with 3D8 scFv. Lung sections from mice at 3 days post challenge were stained with H\&E. Uninfected lungs without treatment [panels (a,d), alveoli; (g,j), bronchiole]; infected lung without treatment [panels $(\mathbf{b}, \mathbf{e})$, alveoli; $(\mathbf{h}, \mathbf{k})$, bronchiole]; and infected lung treated with 3D8 scFv [panels (c,f), alveoli; (i,l), bronchiole].

\subsection{D8 scFv Passes through the Nasal Mucosal Layer and Localizes in Epithelial Cells}

To evaluate the correlations among the reduced histopathological signs, the decrease in viral gene expression and the presence of 3D8 scFv in respiratory epithelial cells, we assessed the localization of 3D8 scFv protein in epithelial cells by immunohistochemistry. 3D8 scFv protein was localized in medium-diameter bronchi and alveoli (Figure 4A). Specifically, strong immunohistochemical staining for 3D8 scFv was observed in the nasal layer, bronchus, and surrounding areas. These results indicated that 3D8 scFv passed through the nasal mucosal layer and penetrated the epithelial cells.

\subsection{The Antiviral Effect in 3D8 ScFv-treated Mice is Due to Its Catalytic Activity against Nucleic Acids}

To rule out an indirect antiviral effect of administration of 3D8 scFv administration through triggering an endogenous immune response, we examined the levels of host immune response genes by qRT-PCR. The levels of transcripts involved in the host pro-inflammatory response (TNF- $\alpha$, IL-6) and known antiviral agents (IFN- $\gamma$ ) were increased in both the control group and the 3D8 scFv 
pre-treated group (Figure 4B). There was no statistically significant difference between the groups in the levels of expression of almost all of the transcripts analyzed. Thus, the antiviral effect of 3D8 $\mathrm{scFv}$ was not due to an indirect immune-related mechanism, but rather a direct result of its intrinsic RNase catalytic activity.

A
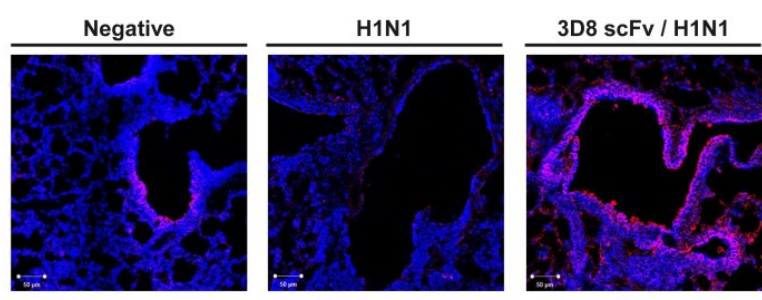

B
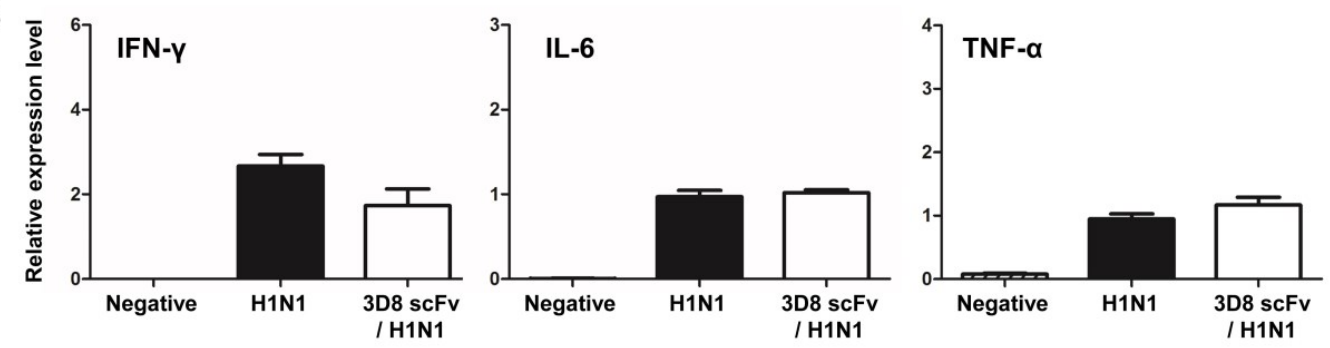

Figure 4. Penetration of 3D8 scFv into the epithelium of the nasal mucosa and analysis of cytokine and chemokine expression. (A) The presence of $3 \mathrm{D} 8 \mathrm{scFv}$ in the epithelium of the nasal mucosa of the lung was detected by immunohistochemistry. Lung tissues were stained with anti-3D8 scFv polyclonal $\mathrm{Ab}$ and visualized using a TRITC-conjugated anti-rabbit secondary $\mathrm{Ab}$ and fluorescence microscopy. Mice were treated with or without 3D8 scFv for 5 days and then challenged. After virus challenge, lung samples were extracted from each group on days 3 and 6 p.i.; (B) mRNA expression of the indicated cytokines and chemokines was measured by qRT-PCR with primers against IFN- $\beta$, IFN- $\gamma$, or GADPH.

\section{Discussion}

Many types of influenza virus have been isolated and characterized in various countries around the world. In particular, recently, the H1N1 influenza virus recently emerged worldwide and caused global pandemic outbreaks in 2009 and 2013-2014. Many countries reported thousands of confirmed cases and several deaths caused by the H1N1 influenza virus $[2,3,7,8,25]$. Thus, there is a huge demand for direct preventive treatments for prevention against H1N1. In this report, we confirmed the preventive activity of 3D8 scFv against H1N1 influenza virus infection through its intrinsic RNase catalytic activity against the viral genome in both MDCK cells and a mouse model system. The expression level of viral genes (HA and NA) was significantly decreased in lung tissues of the 3D8 scFv-treated group (Figure 3B). The virus particle load was also decreased in the alveoli and bronchiole of lungs by immunohistochemistry (Figure 3C). These results suggest that $3 \mathrm{D} 8 \mathrm{scFv}$ can protect mice from H1N1 infection through inhibition of virus multiplication.

Consistent with the direct antiviral effects of 3D8 scFv reported in our previous studies [12-14], viral replication of PRV and HSV was directly inhibited by the intrinsic DNA and RNA hydrolyzing acitivity of 3D8 scFv in transgenic cell lines [12]. In a mouse model system, infection with PRV and MNV was prevented by endogenous expression of 3D8 scFv or by feeding with 3D8 $\mathrm{scFv}$-expressing lactobacillus respectively $[12,14]$. Moreover, $3 \mathrm{D} 8 \mathrm{scFv}$ is able to directly inhibit PRV infection by intraperitoneal (i.p.) injection of purified protein (unpublished data). Therefore, the preventive activity against H1N1 infection observed in both MDCK cells and mice harboring 3D8 $\mathrm{scFv}$ expression in this study provide an example of the direct antiviral activity of 3D8 scFv against H1N1 influenza virus. 
There have been numerous attempts to overcome the respiratory mucosal barrier for efficient delivery of systemically acting drugs. The possibility of using the respiratory tract for drug delivery has been demonstrated in mice for various vaccines against viruses such as influenza, herpes simplex virus, human immunodeficiency virus and human papillomavirus [26]. This approach could allow to access to the central nervous system (CNS) and local/systemic delivery [27]. However, these previous studies have not solved the limitation of protein drug transmission via the respiratory tract, especially for antibody therapies. There are only a few published studies on the therapeutic effects of monoclonal antibodies (mAb) delivered into the airways in animal models of pulmonary inflammation $[28,29]$. Intranasal administration of anti-IL-5 monoclonal antibody was shown to attenuate airway inflammation and hyperresponsiveness in a mouse model [29]. However, in these studies, the protective and neutralizing effect of the administered $\mathrm{mAb}$ was due to the stimulation of an indirect host immune response. In the current study, we tested the ability of 3D8 scFv to inhibit A/NWS/33 H1N1 infection via its intrinsic nuclease activity. We showed that 3D8 scFv penetrated into epithelial cells through the respiratory mucosal layer and finally spread broadly to the lung alveoli (Figure 4A). Furthermore, our immunohistochemistry data demonstrated that the localization of 3D8 scFv in the lung alveoli and epithelial cells could result in direct hydrolysis of the H1N1 genome and/or RNA transcripts through its intrinsic RNase activity. We observed a high level of transmission of 3D8 scFv into the lung tissues by immunohistochemistry but we did not determine the amounts of 3D8 scFv in epithelial cells quantitatively.

Many attempts have been made to increase the permeability and bioavailability of intranasally administered drug. In some cases, peptides or enhancers were fused to drugs. To overcome the difficulty of penetrating the nasal barrier, various other approaches have been utilized including modification of the permeability of nasal membranes by an absorption enhancer or the use of the mucoadhesive system such as a bioadhesive, liquid formulation and microsphere powder [30]. However, 3D8 scFv does not need any further enhancers or modifications to increase its permeability and bioavailability because it can penetrate into epithelial cells through respiratory mucosal layers. $3 \mathrm{D} 8 \mathrm{scFv}$ was previously characterized as a protein that can enter into cells by caveolae-mediated endocytosis [11]. Therefore, this ability of 3D8 scFv to penetrate epithelial cells and the respiratory mucosal layer provides potential as an effective intranasal drug candidate.

Overreaction of the host immune response (i.e., a "cytokine storm") induces a hyperinflammatory process and is involved in the pathogenicity of the influenza virus [31,32]. A tight correlation between the induction of genes involved in the inflammatory response and increased resistance against virus infection has been reported. Transcript levels of inducible nitric oxide synthase (iNOS) remain high in cells infected with several viruses, including HSV and influenza virus [33]. Similarly, levels of IL-6 and TNF- $\alpha$ correlated positively with lung inflammation and vascular dysfunction [32]. Thus, to determine whether the antiviral effect observed in our study was caused by direct RNase activity of $3 \mathrm{D} 8 \mathrm{scFv}$ or indirect activation of an endogenous antiviral response, we measured the expression levels of marker genes involved in the inflammation pathway. As shown in Figure 4B, levels of proinflammatory cytokines (IL-6, TNF- $\alpha$ ) and antiviral proteins (IFN- $\gamma$ ) were significantly increased in the H1N1-infected group compared with the non-infected control group. However, the levels of transcripts of the H1N1-infected group were similar to those of the 3D8 scFv-treated group. These results indicated that the antiviral effects of 3D8 scFv against H1N1 infection were due to the direct intrinsic RNase activity of 3D8 scFv rather than a host immune response.

In conclusion, we demonstrated that the RNase activity of 3D8 scFv could be effectively employed in vivo as an antiviral agent against influenza virus by delivering the protein to the respiratory cavity via intranasal administration. The unique cell penetration properties of 3D8 scFv protein combined with its intrinsic RNase activity suggest that $3 \mathrm{D} 8 \mathrm{scFv}$ might have potential as a novel antiviral drug candidate. 
Acknowledgments: This work was supported by a grant from the Agenda (No. PJ0102012015) from the Rural Development Administration (RDA) of Korea.

Author Contributions: S.C. and S.L. conceived and designed the experiments; S.C., H.N.Y., P.M.H., S,C., K.E.K., E.J.K., M.J.C. and J.H. performed the experiments; S.C. analyzed the data; G.L. contributed reagents/materials/analysis tools; S.J.B. provided the animal study data; C.S.S. provided conceptual advice for the in vivo virus challenging experiments; S.C. and S.L. wrote the paper.

Conflicts of Interest: None of the authors reported a conflict. All authors have submitted the ICMJE Form for Disclosure of Potential Conflicts of Interest. Conflicts that the editors consider relevant to the content of the manuscript have been disclosed.

\section{References}

1. Tang, J.W.; Shetty, N.; Lam, T.T.; Hon, K.L. Emerging, novel, and known influenza virus infections in humans. Infect. Dis. Clin. N. Am. 2010, 24, 603-617. [CrossRef] [PubMed]

2. Perez-Padilla, R.; de la Rosa-Zamboni, D.; Ponce de Leon, S.; Hernandez, M.; Quinones-Falconi, F.; Bautista, E.; Ramirez-Venegas, A.; Rojas-Serrano, J.; Ormsby, C.E.; Corrales, A.; et al. Pneumonia and respiratory failure from swine-origin influenza a (H1N1) in mexico. N. Engl. J. Med. 2009, 361, 680-689. [CrossRef] [PubMed]

3. Huang, S.S.; Lin, Z.; Banner, D.; Leon, A.J.; Paquette, S.G.; Rubin, B.; Rubino, S.; Guan, Y.; Kelvin, D.J.; Kelvin, A.A. Immunity toward H1N1 influenza hemagglutinin of historical and contemporary strains suggests protection and vaccine failure. Sci. Rep. 2013, 3. [CrossRef] [PubMed]

4. Boltz, D.A.; Aldridge, J.R., Jr.; Webster, R.G.; Govorkova, E.A. Drugs in development for influenza. Drugs 2010, 70, 1349-1362. [CrossRef] [PubMed]

5. Sheu, T.G.; Fry, A.M.; Garten, R.J.; Deyde, V.M.; Shwe, T.; Bullion, L.; Peebles, P.J.; Li, Y.; Klimov, A.I.; Gubareva, L.V. Dual resistance to adamantanes and oseltamivir among seasonal influenza A(H1N1) viruses: 2008-2010. J. Infect. Dis. 2011, 203, 13-17. [CrossRef] [PubMed]

6. Webster, D.; Li, Y.; Bastien, N.; Garceau, R.; Hatchette, T.F. Oseltamivir-resistant pandemic H1N1 influenza. Can. Med. Assoc. J. 2011, 183, E420-E422. [CrossRef] [PubMed]

7. Flannery, B.; Thaker, S.N.; Clippard, J.; Monto, A.S.; Ohmit, S.E.; Zimmerman, R.K.; Nowalk, M.P.; Gaglani, M.; Jackson, M.L.; Jackson, L.A.; et al. Interim estimates of 2013-14 seasonal influenza vaccine effectiveness-United States, February 2014. Morb. Mortal. Wkly. Rep. 2014, 63, 137-142.

8. Barr, I.G.; Russell, C.; Besselaar, T.G.; Cox, N.J.; Daniels, R.S.; Donis, R.; Engelhardt, O.G.; Grohmann, G.; Itamura, S.; Kelso, A.; et al. Who recommendations for the viruses used in the 2013-2014 northern hemisphere influenza vaccine: Epidemiology, antigenic and genetic characteristics of influenza $\mathrm{A}(\mathrm{H} 1 \mathrm{~N} 1) \mathrm{pdm} 09, \mathrm{~A}(\mathrm{H} 3 \mathrm{~N} 2)$ and B influenza viruses collected from October 2012 to January 2013. Vaccine 2014, 32, 4713-4725. [PubMed]

9. Kim, Y.R.; Kim, J.S.; Lee, S.H.; Lee, W.R.; Sohn, J.N.; Chung, Y.C.; Shim, H.K.; Lee, S.C.; Kwon, M.H.; Kim, Y.S. Heavy and light chain variable single domains of an anti-DNA binding antibody hydrolyze both double- and single-stranded dnas without sequence specificity. J. Biol. Chem. 2006, 281, 15287-15295. [CrossRef] [PubMed]

10. Kwon, M.H.; Lee, M.S.; Kim, K.H.; Park, S.; Shin, H.J.; Jang, Y.J.; Kim, H.I. Production and characterization of an anti-idiotypic single chain $\mathrm{fv}$ that recognizes an anti-DNA antibody. Immunol. Investig. 2002, 31, 205-218. [CrossRef]

11. Jang, J.Y.; Jeong, J.G.; Jun, H.R.; Lee, S.C.; Kim, J.S.; Kim, Y.S.; Kwon, M.H. A nucleic acid-hydrolyzing antibody penetrates into cells via caveolae-mediated endocytosis, localizes in the cytosol and exhibits cytotoxicity. Cell. Mol. Life Sci. 2009, 66, 1985-1997. [CrossRef] [PubMed]

12. Lee, G.; Yu, J.; Cho, S.; Byun, S.-J.; Kim, D.H.; Lee, T.-K.; Kwon, M.-H.; Lee, S. A nucleic-acid hydrolyzing single chain antibody confers resistance to DNA virus infection in hela cells and c57bl/6 mice. PLoS Pathog. 2014, 10, e1004208. [CrossRef] [PubMed]

13. Jun, H.R.; Pham, C.D.; Lim, S.I.; Lee, S.C.; Kim, Y.S.; Park, S.; Kwon, M.H. An rna-hydrolyzing recombinant antibody exhibits an antiviral activity against classical swine fever virus. Biochem. Biophys. Res. Commun. 2010, 395, 484-489. [CrossRef] [PubMed] 
14. Hoang, P.M.; Cho, S.; Kim, K.E.; Byun, S.J.; Lee, T.-K.; Lee, S. Development of lactobacillus paracasei harboring nucleic acid-hydrolyzing $3 \mathrm{~d} 8 \mathrm{scfv}$ as a preventive probiotic against murine norovirus infection. Appl. Microbiol. Biotechnol. 2015, 99, 2793-2803. [CrossRef] [PubMed]

15. Neutra, M.R.; Kozlowski, P.A. Mucosal vaccines: The promise and the challenge. Nat. Rev. Immunol. 2006, 6, 148-158. [PubMed]

16. Illum, L. Nasal drug delivery-Possibilities, problems and solutions. J. Control. Release 2003, 87, 187-198. [CrossRef]

17. Romeo, V.D.; deMeireles, J.; Sileno, A.P.; Pimplaskar, H.K.; Behl, C.R. Effects of physicochemical properties and other factors on systemic nasal drug delivery. Adv. Drug Deliv. Rev. 1998, 29, 89-116. [PubMed]

18. Patton, J.S.; Platz, R.M. (D) routes of delivery: Case studies: (2) pulmonary delivery of peptides and proteins for systemic action. Adv. Drug Deliv. Rev. 1992, 8, 179-196. [CrossRef]

19. Klingenberg, R.; Lebens, M.; Hermansson, A.; Fredrikson, G.N.; Strodthoff, D.; Rudling, M.; Ketelhuth, D.F.; Gerdes, N.; Holmgren, J.; Nilsson, J.; et al. Intranasal immunization with an apolipoprotein b-100 fusion protein induces antigen-specific regulatory $\mathrm{t}$ cells and reduces atherosclerosis. Arterioscler. Thromb. Vasc. Biol. 2010, 30, 946-952. [CrossRef]

20. Sloat, B.R.; Cui, Z. Evaluation of the immune response induced by a nasal anthrax vaccine based on the protective antigen protein in anaesthetized and non-anaesthetized mice. J. Pharm. Pharmacol. 2006, 58, 439-447. [CrossRef] [PubMed]

21. Youn, H.N.; Lee, D.H.; Lee, Y.N.; Park, J.K.; Yuk, S.S.; Yang, S.Y.; Lee, H.J.; Woo, S.H.; Kim, H.M.; Lee, J.B.; et al. Intranasal administration of live lactobacillus species facilitates protection against influenza virus infection in mice. Antivir. Res. 2012, 93, 138-143. [CrossRef] [PubMed]

22. Ramos-Vara, J.A. Technical aspects of immunohistochemistry. Vet. Pathol. 2005, 42, 405-426. [CrossRef] [PubMed]

23. Rozen, S.; Skaletsky, H. Primer3 on the www for general users and for biologist programmers. Methods Mol. Biol. 2000, 132, 365-386. [PubMed]

24. Venables, W.N.; Ripley, B.D. Modern Applied Statistics with S; Springer: Berlin, Germany, 2002.

25. Catania, J.; Que, L.G.; Govert, J.A.; Hollingsworth, J.W.; Wolfe, C.R. High intensive care unit admission rate for 2013-2014 influenza is associated with a low rate of vaccination. Am. J. Respir. Crit. Care Med. 2014, 189, 485-487. [CrossRef] [PubMed]

26. Davis, S.S. Nasal vaccines. Adv. Drug Deliv. Rev. 2001, 51, 21-42. [CrossRef]

27. Illum, L. Nasal drug delivery: New developments and strategies. Drug Discov. Today 2002, 7, 1184-1189. [CrossRef]

28. Abraham, W.M.; Sielczak, M.W.; Ahmed, A.; Cortes, A.; Lauredo, I.T.; Kim, J.; Pepinsky, B.; Benjamin, C.D.; Leone, D.R.; Lobb, R.R.; et al. Alpha 4-integrins mediate antigen-induced late bronchial responses and prolonged airway hyperresponsiveness in sheep. J. Clin. Investig. 1994, 93, 776-787. [CrossRef] [PubMed]

29. Shardonofsky, F.R.; Venzor, J., 3rd; Barrios, R.; Leong, K.P.; Huston, D.P. Therapeutic efficacy of an anti-il-5 monoclonal antibody delivered into the respiratory tract in a murine model of asthma. J. Allergy Clin. Immunol. 1999, 104, 215-221. [CrossRef]

30. Anik, S.T.; McRae, G.; Nerenberg, C.; Worden, A.; Foreman, J.; Hwang, J.Y.; Kushinsky, S.; Jones, R.E.; Vickery, B. Nasal absorption of nafarelin acetate, the decapeptide [d-nal(2)6)]lhrh, in rhesus monkeys. I. J. Pharm. Sci. 1984, 73, 684-685. [CrossRef] [PubMed]

31. de Jong, M.D.; Simmons, C.P.; Thanh, T.T.; Hien, V.M.; Smith, G.J.; Chau, T.N.; Hoang, D.M.; Chau, N.V.; Khanh, T.H.; Dong, V.C.; et al. Fatal outcome of human influenza a (h5n1) is associated with high viral load and hypercytokinemia. Nat. Med. 2006, 12, 1203-1207. [CrossRef] [PubMed] 
32. Wang, S.; Le, T.Q.; Kurihara, N.; Chida, J.; Cisse, Y.; Yano, M.; Kido, H. Influenza virus-cytokine-protease cycle in the pathogenesis of vascular hyperpermeability in severe influenza. J. Infect. Dis. 2010, 202, 991-1001. [CrossRef] [PubMed]

33. Suliman, H.B.; Ryan, L.K.; Bishop, L.; Folz, R.J. Prevention of influenza-induced lung injury in mice overexpressing extracellular superoxide dismutase. Am. J. Physiol. Lung Cell. Mol. Physiol. 2001, 280, L69-L78. [PubMed]

(c) (C) 2015 by the authors; licensee MDPI, Basel, Switzerland. This article is an open access article distributed under the terms and conditions of the Creative Commons by Attribution (CC-BY) license (http://creativecommons.org/licenses/by/4.0/). 